\title{
Hypopigmented Mycosis Fungoides in a 7-Year-Old Boy
}

\author{
Felipe Nazareth", Maria Victoria Quaresma, Fred Bernardes, Carlos Gustavo Carneiro Castro, \\ Edilbert Pellegrini Nahn, Jose Augusto da Costa Nery, Mayra Carrijo Rochael, Omar Lupi
}

Department of Dermatology, Policlínica Geral do Rio de Janeiro, Rio de Janeiro, Brazil.

Email: " nazarethfelipe@hotmail.com

Received December $22^{\text {nd }}, 2011$; revised January $26^{\text {th }}, 2012$; accepted February $9^{\text {th }}, 2012$

\begin{abstract}
Hypopigmented mycosis fungoides (HMF) is an uncommon variant of cutaneous T-cell lymphoma. It is more frequent in dark-skinned people, particularly children. The HMF diagnose is difficult, especially in early stages because this condition resembles benign skin diseases. Thus is histopathological analysis very important for the diagnosis. We report a case of a 7-year-old child with widespread HMF confirmed by histopathology that showed cells tagging along the der$\mathrm{mal} /$ epidermal junction and extending into the epidermis in a pattern of epidermotropism and focal cell aggregates in the epidermis (Pautrier's microabscess). We demonstrate the importance of clinical suspicion for this cutaneous neoplasia in patients with hypopigmentated lesions.
\end{abstract}

Keywords: Hypopigmented; Child; Mycosis Fungoides

\section{Introduction}

Mycosis fungoides (MF), the most common type of cutaneous T-cell lymphoma is more frequent in the elderly. Although it is rare in childhood and adolescence, there has been an increased recognition that MF may arise in children and young adults [1,2]. Diagnosis is difficult in the early stage of the disease because it mimics several benign skin disorders including eczema, psoriasis, and contact dermatitis. Multiple biopsies may be necessary to confirm the diagnosis [1]. The most common findings are erythematous, scaly, and hypopigmented macules [3]. The etiology of MF remains unknown but various theories have been postulated, such as chronic antigenic stimulation, atopy and, occupational, environmental, and viral exposures $[1,4]$. We report a case of hypopigmented mycosis fungoides (HMF) in a dark-skinned 7-year-old boy.

\section{Case Report}

A 7-year-old boy presented with a 1-year and 5 months history of erythematous patches which turned into hypopigmentation (Figures 1 and 2). The first patch was noticed on the left arm after intense sun exposure. The patient had no other significant medical data and there was no use of any medication. On skin examination, multiple hypopigmented and oval macules and patches were observed on the trunk, face and limbs covering more than $10 \%$ of the skin. The lesions were accom-

"Corresponding author.

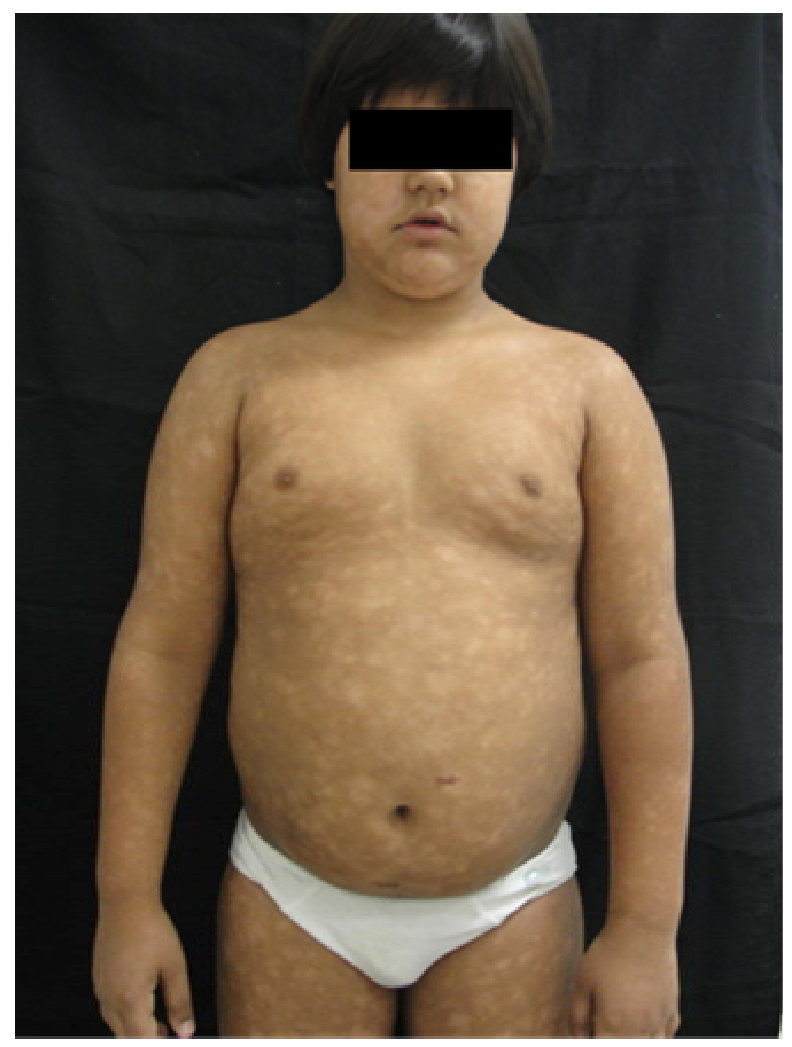

Figure 1. A 7-year-old boy presenting with hypopigmented macules on limbs, trunk and abdomen.

panied by discrete pruritus and the skin sensibility on the patches was normal. General physical examination re- 


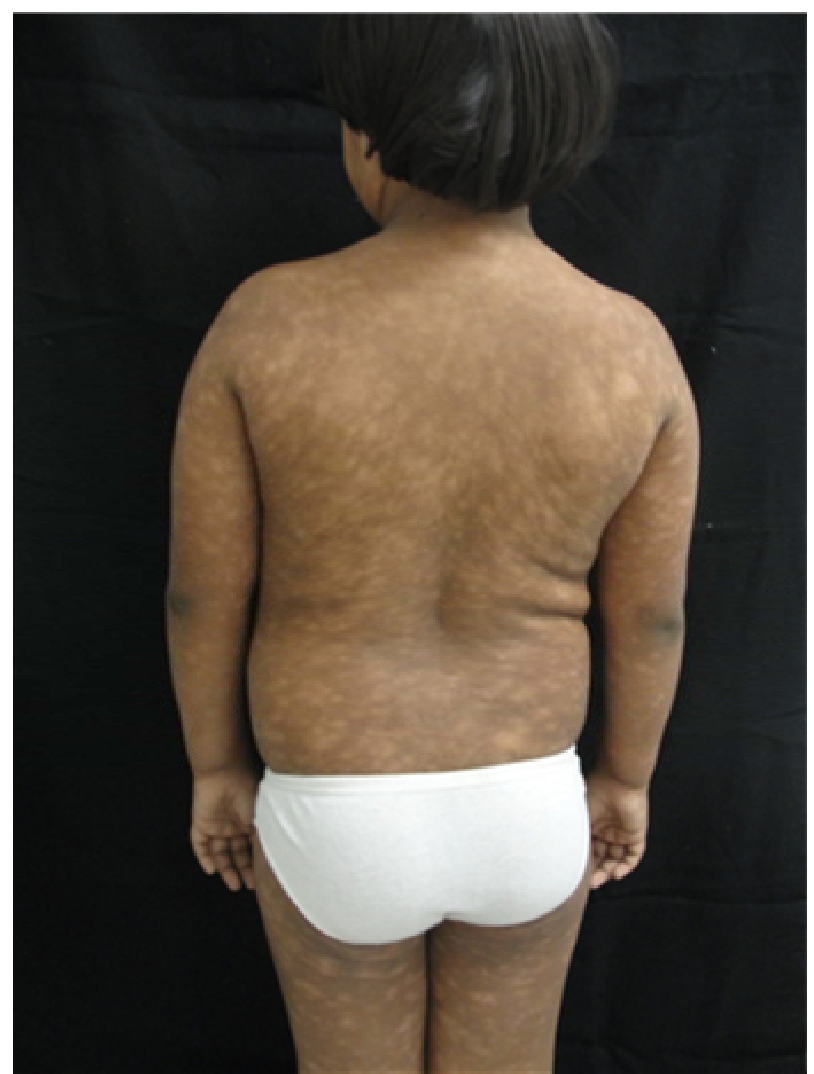

(a)

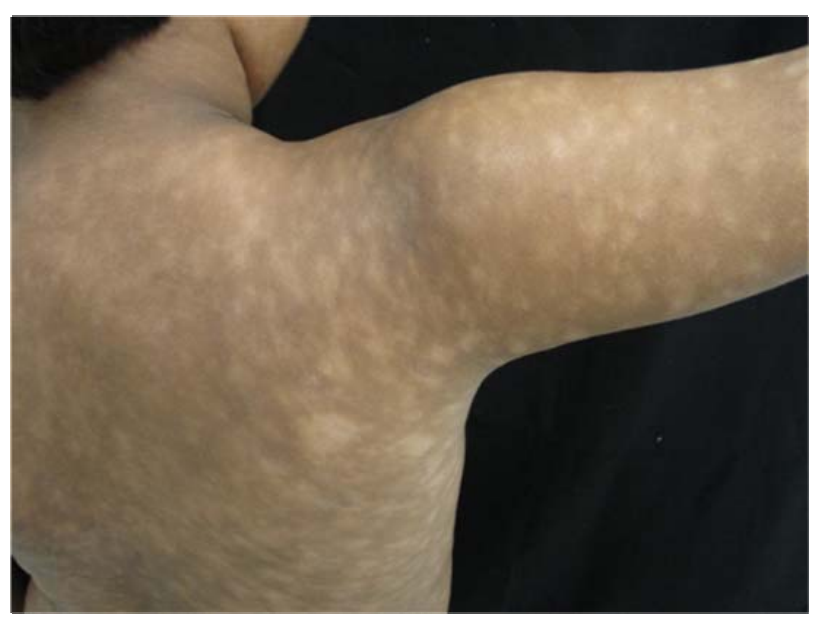

(b)

Figure 2. (a) Generalized hypopigmented macules covering over $10 \%$ of the body surface area; (b) Hypopigmented macules/patches on trunk e superior right limb.

vealed no lymphadenopathy or hepatosplenomegaly. The hypopigmented patch's biopsy on the abdomen revealed cells tagging along the dermal/epidermal junction and extending into the epidermis in a pattern of epidermotropism. Some of these cells had perinuclear halos and focal aggregates were noticed in the epidermis (Pautrier's microabscess). Immunophenotypical analysis revealed that neoplastic cells were CD3 positive, which is a pan T-cell marker. The lymphocytes were mostly of the $\mathrm{T}$ helper CD4 positive (90\%) phenotype but $\mathrm{T}$ suppressor/cytotoxic CD8 positive cells were also detected in a small proportion $(10 \%)$. Complete blood cell count with examination for Sezary cells, chest radiography and abdominal ultrasonography did not show any abnormalities. A diagnosis of stage 1B [5] hypopigmented mycosis fungoides was established based on clinical and histopathological/immunophenotypical findings. Therefore narrowband UVB therapy three times a week was planned (Figures 3 and 4).

\section{Discussion}

HMF is an atypical, rare and unique variant of MF characterized by solely hypopigmented patches or more commonly in combination with erythematous patches or plaques, usually observed in dark skinned individuals, and exceedingly rare in Caucasians and others with fair skin types [6,7].

The mechanism of the hypopigmentation in this MF variant is still unclear. It has been postulated that atypical lymphoid cells infiltrating the epidermis cause melanocyte degeneration and abnormal melanogenesis as a result of non-specific cell injury [8]. In contrast, other authors proposed that the loss of pigment results from a defect in melanosome transfer from melanocyte to keratinocytes $[9,10]$.

The epidermal infiltrate in hypopigmented MF is reported to be predominantly of CD8-positive lymphocytes $[11,12]$, however, our patient had an epidermal infiltrate with mostly CD4-positive lymphocytes.

HMF should be included in the differential diagnosis of any persistent hypopigmented macule or patch that is resistant to treatment. It is emphasized that this variant

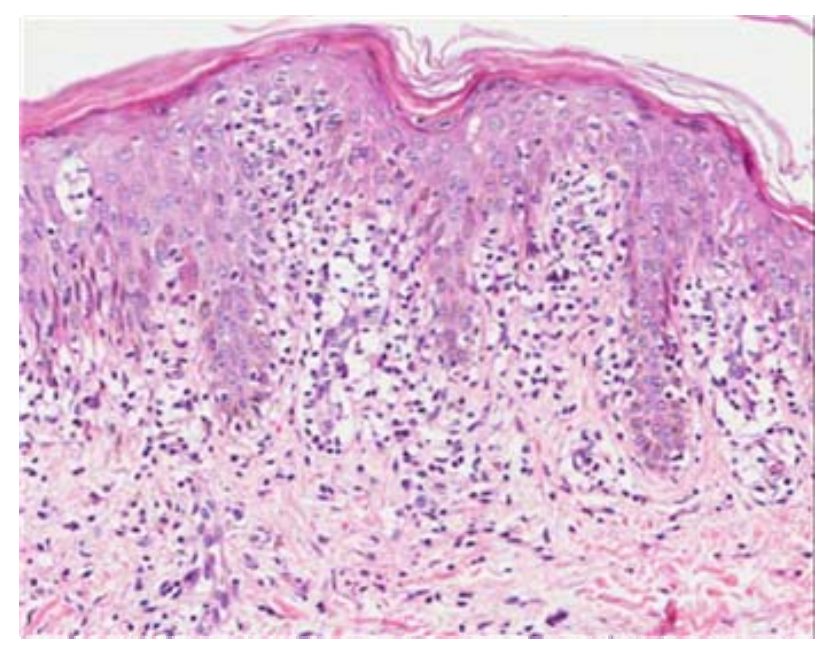

Figure 3. Histopathological analysis showing on high-power view a lymphocytic infiltrate in the epidermis. 


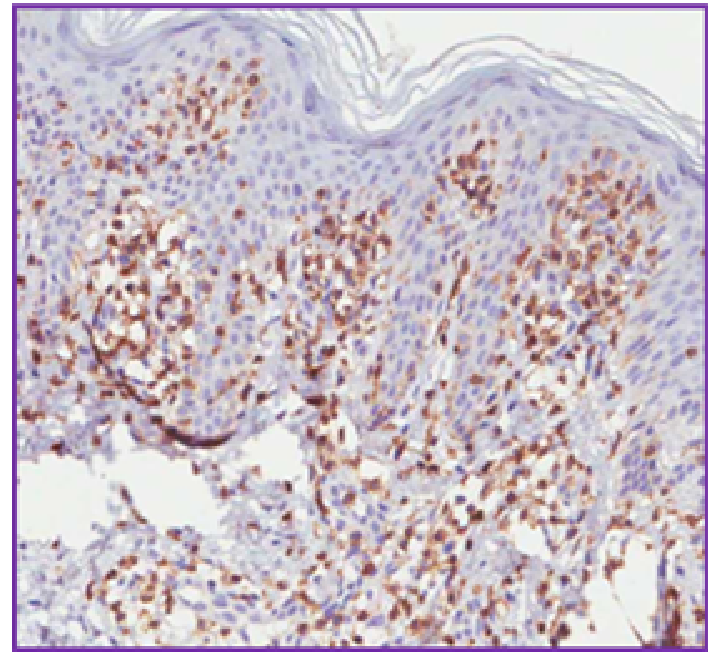

(a)

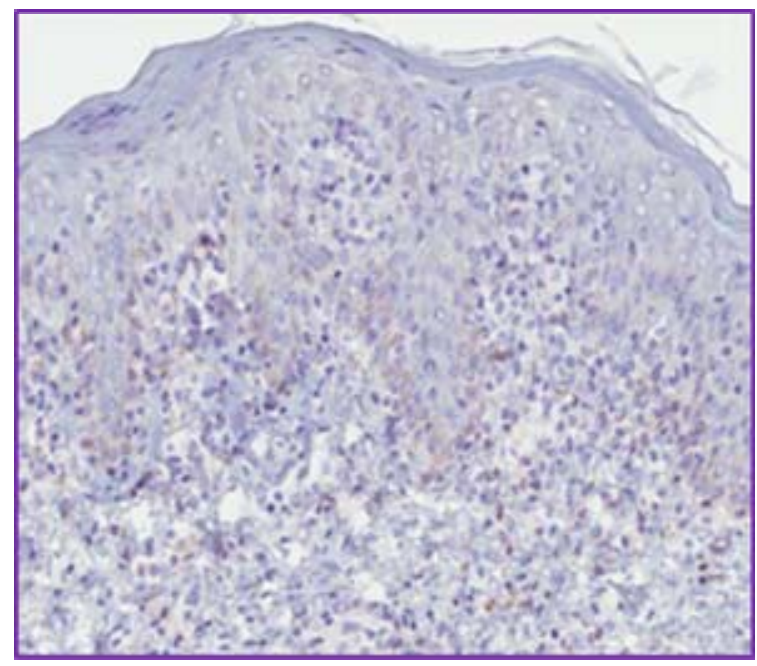

(c)

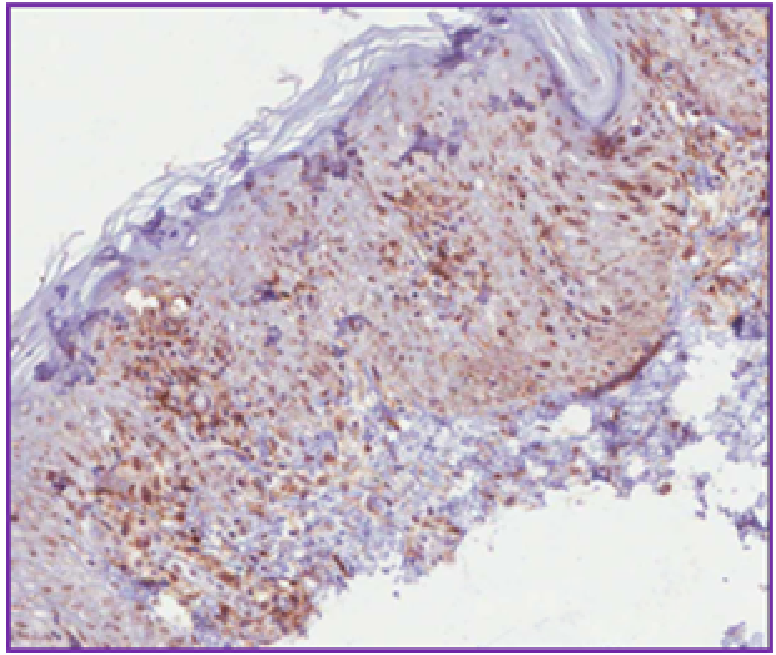

(b)

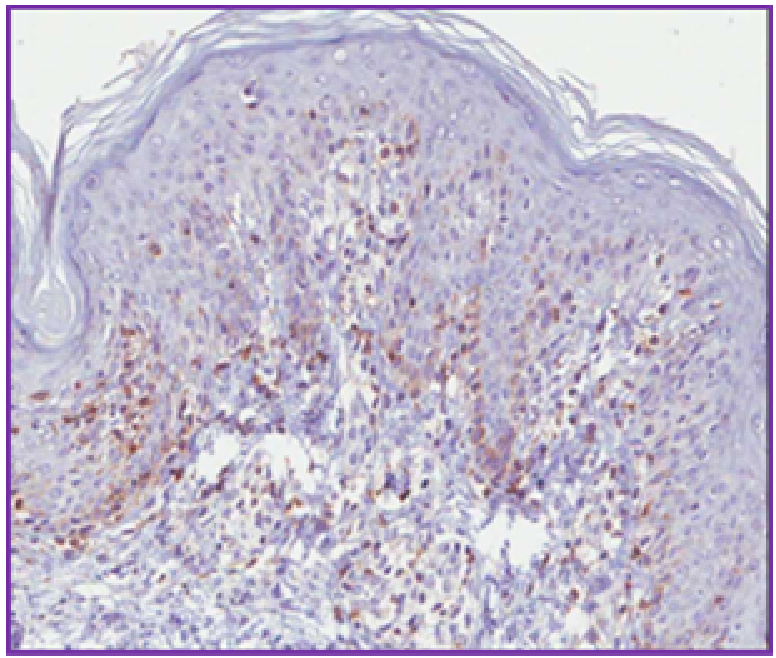

(d)

Figure 4. Immunohistoquemical stanning showing high positivity to CD3 (a) and to CD4 (b), whereas CD8 (c) and CD7 (d) present lower positivity.

usually presents at a younger age than the classical MF. Sequential biopsies are recommended if the diagnosis remains in doubt. Although the majority of cases have a benign course we concluded that it is essential to stage this disease clinically since occasional cases had an unfavorable progression. Furthermore, follow up of the patient is clearly indicated since recurrence is common and some cases behave aggressively $[6,10]$.

Long follow-ups have demonstrated that hypopigmented MF responds well to UVA and UVB, or topical mechlorethamine, resulting in remission for years [12]. We decided to initiate UVB narrow band therapy for our patient after staging his disease (stage 1B) since we believe that this option is a safe one in this age and also because it has been shown to be effective to treat this disease [1].

\section{REFERENCES}

[1] N. Onsun, Y. Kural, O. Su, et al., "Hypopigmented Mycosis Fungoides Associated with Atopy in Two Children," Pediatric Dermatology, Vol. 23, No. 5, 2006, pp. 493-496.

[2] J. J. Crowly, A. Nikko, A. Varghese, et al., "Mycosis Fungoides in Young Patients: Clinical Characteristics and Outcome," Journal of the American Academy of Dermatology, Vol. 38, No. 5, 1998, pp. 696-701. doi:10.1016/S0190-9622(98)70198-7

[3] S. E. Whitmore, et al., "Hypopigmented Mycosis Fungoides," Archives of Dermatology, Vol. 130, No. 4, 1994, pp. 476-480.

doi:10.1001/archderm.1994.01690040080012

[4] E. Tuyp, A. Burgoyne, T. Aitchison, et al., "A CaseControl Study of Possible Causative Factors in Mycosis Fungoides," Archives of Dermatology, Vol. 123, No. 2, 
1987, pp. 196-200. doi:10.1001/archderm.123.2.196

[5] Y. H. Kim, et al., "Long-Term Outcome of 525 Patients with Mycosis Fungoides and Sézary Syndrome," Archives of Dermatology, Vol. 139, No. 7, 2003, pp. 857-866.

[6] A. Di Landro, L. Marchesi, L. Naldi, T. Motta and T. Cainelli, "A Case of Hypopigmented Mycosis Fungoides in a Young Caucasian Boy," Pediatric Dermatology, Vol. 14, No. 6, 1997, pp. 449-452. doi:10.1111/j.1525-1470.1997.tb00687.x

[7] E. Sezer, T. Sezer, A. Senayli, D. Koseoglu and N. Filiz, "Hypopigmented Mycosis Fungoides in a Caucasian Child," European Journal of Dermatology, Vol. 16, No. 5, 2006, p. 584.

[8] S. M. Breathnach, P. H. Mckee and N. P. Smith, "Hypopigmented Mycosis Fungoides: Report of Five Cases with Ultrastructural Observations," British Journal of Dermatology, Vol. 106, No. 6, 1982, pp. 643-649. doi:10.1111/j.1365-2133.1982.tb11678.x
[9] D. J. Goldberg, R. A. Schinella and P. Kechijian, "Hypopigmented Mycosis Fungoides: Speculations about the Mechanism of Hypopigmentation," The American Journal of Dermatopathology, Vol. 8, No. 4, 1986, pp. 326-330. doi:10.1097/00000372-198608000-00009

[10] J. T. Al-Ratrout, M. Al-Nazer and N. A. Ansari, "Hypopigmented Mycosis Fungoides in a Twenty-Year-Old Saudi Woman with Fair Skin," Indian Journal of Dermatology, Vol. 51, No. 2, 2006, pp. 115-117. doi:10.4103/0019-5154.26932

[11] L. El-Shabrawi-Caelen, L. Cerroni, L. J. Medeiros and T. H. McCalmont, "Hypopigmented Mycosis Fungoides: Frequent Expression of a CD8+ T-Cell Phenotype," The American Journal of Surgical Pathology, Vol. 26, No. 4, 2002, pp. 450-457. doi:10.1097/00000478-200204000-00006

[12] A. Manzur and S. T. H. Zaid, "Hypopigmented Mycosis Fungoides in a 10-Year-Old Boy," Dermatology Online Journal, Vol. 12, No. 6, 2006, p. 21. 